\title{
Gabriela Mistral y la identidad tensionada de nuestra Modernidad
}

\author{
Olga Grandón Lagunas \\ Universidad de Chile \\ olga-grandon@yahoo.com
}

\section{Resumen}

La vinculación problemática de la prosa mistraliana con el desarrollo de la M odernidad literaria en América Latina es reconocida por numerosos autores. Bajo el pretexto de esta obra, intento desarrollar un ejemplo del modo con que los escritores latinoamericanos de comienzos del siglo XX han asimilado la M odernidad europea, específicamente, estudiando la literatura en prosa de $G$ abriela $M$ istral. Esto significa responder cuáles son las condiciones de esta apropiación, cuáles son sus límites, cuál es su organización, sus continuidades y discontinuidades.

Palabras claves: M odernidad, identidad, G abriela M istral y literatura chilena.

\section{Abstract}

The link of the issue of the M istralian (as in Gabriela M istral's) prose with the development of the literary modernity in Latin America is recognised by several authors. Bearing this work in mind, I intend to develop an example in the way in which the Latin American writers at the begining of the 20th century have assimilated european modernity specifically studying the work of prose literature of $\mathrm{G}$ abriela M istral.This means to study which are the conditions of appropriation, its limitations, organization, continuities and discontinuities.

Keywords: M odernity, identity, Gabriela M istral and chilean literature.

Recibido: 16-06-2004 Aceptado: 24-08-2004

E N ESTE artículo abordo el problema de la vinculación problemática de la - prosa mistraliana con el desarrollo de la M odernidad, a partir de la etapa "modernista-mundonovista" de esta obra (N ómez 1996). Estudio el tema en una miscelánea de textos publicados originariamente en periódicos; pero en su mayoría recopiladosen publicaciones póstumas: "El patriotismo de nuestra hora" 
(1919), "A la mujer mexicana (1923)", "D on Vasco de Quiroga" (1923), "G abriela piensa en la madre ausente" (1923), "LosD erechos del N iño" (1928), "El pueblo araucano" (1932), "Fray Bartolomé" (1932), "Pequeño mapa audible de Chile" (1934), "Recado sobreel Q uetzalcóatl" (1936), "Recado sobrelos T lálocs" (1936), "La madre: obra maestra" (1940), "Recado sobre M ichoacán" (1944) y "Algo sobre el pueblo quechua" (1947)1.

Sobre la base de este corpus, postulo al gunas hipótesis sobre las diversas formas de enfrentar críticamentela M odernidad, donde percibo una fisura referida a la apropiación integrada, a la vez que crítica, de lo foráneo y colonizador con lo propio, altamentetensionada y con un componente genérico-sexual, pues la crítica mistraliana a la represión y subalternidad de la mujer se da a través de la recuperación de una identidad transgresora y tránsfuga, doble y escindida, donde la sublimación de una femineidad perturbadora es un tema recurrente en los textos comentados y, me atrevo a postular, en toda su obra. Dicha postura está claramente motivada por la crítica de $\mathrm{M}$ istral a una sociedad moderna mercantilizada, que ha hecho de la violencia y la pobreza sus mayores lacras. Respecto de esto último, la tensión polémica entre oralidad y escritura, cultura colonizadora eurocéntrica y aborigen latinoamericana, cultura popular oral y privilegiada letrada, se manifiesta tanto en el plano de las significaciones como en los planos formal, lingüístico y retórico de los textos, tornándolos ambivalentes.

Es en el nivel de los temas donde la obra en prosa de G abriela M istral muestra sus nexos y concomitancias respecto de las producciones literarias latinoamericanas del mismo período, en las cuales se percibe un hiato, fisura, referida a la apropiación integrada de lo foráneo y colonizador con lo propio, puesto que no hay un carácter integrador en las etapas de aculturación, recepción y recomposición sociocultural, que el proceso de mestizaje latinoamericano implicó según los estudios que reseño brevemente a continuación.

En nuestro continente el problema del mestizaje es definido como encuentro (más bien desencuentro) entre universos culturales distintos causantes de "transculturación" (desculturación y neoculturación) (O rtiz 1994) con domi-

${ }^{1}$ Indico las fechas originarias de su publicación en periódicos; pero cito las referencias desde las recopilaciones póstumas de la prosa mistraliana.

2 Fernando 0 rtiz define el vocablo transculturación, dela siguiente manera: "Expresa me jor las diferentes fases del proceso transitivo de una cultura a otra, porque éste no consiste solamente en adquirir una cultura distinta, que es lo queen rigor indica la voz anglo-americana aculturación, sino que el proceso implica también necesariamente pérdida o desarraigo de una cultura precedente, lo que pudiera decirse una parcial desculturación, y, además, significa la consiguiente creación de nuevos fenómenos culturales que pudieran denominarse de neoculturación" (O rtiz 1994: 96) 
nancia de "aculturación" (imposición cultural deuna sociedad sobre otra)². Esto es, en Latinoamérica, la transculturación se da como aculturación de lo moderno sobre lo tradicional y significa quela relación entre los el ementos de M odernidad y los elementos de la tradición consiste en que los primeros se imponen sobre los segundos, ya sea descalificándolos, suplantándolos o simplemente haciendo caso omiso a su existencia. Angel Rama comenta el mismo concepto, afirmando que "traza un muy variado esquema de pugnas" (Rama 1987:34) y concluyendo que en esteproceso habría "pérdidas, selecciones, redescubrimientos e incorporaciones", que se resuelven en una "reestructuración general" (Rama 1987: 39). Esto significa que en un proceso de "desculturación parcial" se produce una selección de elementos de las culturas invasora y autóctona, respectivamente, junto con la invención de otros elementos, cuyo resultado es una suerte de "neocultura" (O rtiz 1994).

Es así como las obras literarias latinoamericanas del período en que publica $M$ istral suelen mostrar este conflicto abierto, tal como ocurre en los textos de la autora que anal izo, apoyándome especialmente en las tensiones de significación que muestran un carácter contradictorio y perturbador. Presento, entonces, una clasificación inicial de los temas, que, dado lo expuesto, define tres tensiones fundamentales: la etno-racial, la sexo-genérica y la utópica.

Se hace necesario aquí aclarar la distinción entre M odernidad y M odernismo. Entiendo a la primera, en términos generales, como tiempo de crisis histórica, que coincide con el auge histórico del capital ismo y el desencanto y secularización del mundo. Entonces, la modernización afecta lo social, lo cultural y lo personal. Su especificidad en la esfera cultural (saberes, creencias y valores) está signada de manera distinta para el mundo occidental europeo y para el mundo latinoamericano. En el primero, la llustración fue el hito principal del proceso de formación cultural con que se identifica la modernización occidental, este proceso se desarrolló entre fines del siglo XVI y fines del XX (Berman 1989). A diferencia de la M odernidad, el M odernismo alude a un período artístico de unos quince años, iniciado en Europa hacia 1890 y terminado en los primeros años del siglo XX; aunque no tuvo la misma denominación para todos los países, por ejemplo, en España sellamó de esta manera, pero no en Francia donde el período coincide con el Simbolismo, desarrollado en el plano de las artes principalmente.

Para Latinoamérica el M odernismo es el movimiento quea fines del siglo XIX se desarrolla en todas las esferas literarias de su mundo ilustrado. N umerosos estudios coinciden en que este movimiento se desarrolló entre 1880 y el término dela Primera G uerra M undial, aproximadamente, señalándose sus hitos cronológicos 
entre 1888, año de la publicación de Azul de Rubén D arío y 1916, año de la muerte del mismo autor. La tónica característica de este proceso es constituirse como respuestas y propuestas a la modernización vertiginosa que vivía el mun$\mathrm{do}^{3}$.

Los estudios actuales sobre M odernidad coinciden en el análisis de que, pese al impacto cultural que significó en las sociedades latinoamericanas la expansión del capitalismo en 0 ccidente, éstas consiguieron una modernización tangencial y hasta distorsionada. Entonces, hubo una modernización deficiente con un M odernismo desbordante, entendidos estos términos como los he desarrollado en este artículo. Por ejemplo, Bernardo Subercaseaux aclara que la modernización fue un proceso "inorgánico, disparejo y desequilibrado", que tuvo casi como regla general la convivencia de lo moderno con lo arcaico, y acota que en casi toda la región tuvo un marco común que caracterizó el fin del siglo XIX:

Un marco que en lo ideológico estuvo dado por un afán modernizador de cuño ilustrado positivista, en lo económico por la incorporación estructural al mercado capitalista mundial, en lo social por la inmigración masiva y la presencia de nuevos actores, y en lo político por la instauración de regímenes teóricamenteliberalespero en la práctica fuertemente restrictivos(Subercaseaux 1998: 145).

D esarrollo ahora la mencionada clasificación temática tensional de la prosa en estudio:

${ }^{3}$ Se entiende por modernización, a un proceso de transformación de las sociedades, con la connotación de renovación que el término implica, especialmente en el ámbito de la cultura. Para Latinoamérica este proceso, situado entre las últimas décadas del siglo XIX y la primera del siglo XX, se caracteriza por tres factores principales, que procedo a glosar, basándome en dos fuentes: el capítulo titulado "M odernismo (H ispanoamérica)", del Diccionario Encidopé dico de las L etras de América Latina (M ontaldo y O sorio 1996), y el titulado "El M odernismo en Chile", del D iccionario de movimientos y grupos literarios chilenos" (M uñoz y 0 elker 1993):

1. Un desplazamiento del sector más tradicional de la oligarquía (Ios terratenientes) hacia una naciente burguesía proveniente de la minería, la banca y el comercio, provocando la fusión de ambos sectores en la aristocracia tradicional, con la consiguiente transformación dela estructura social de Chile, creando, por consiguiente, un crecimiento decapas medias y proletariado.

2. La inserción deAmérica Latina en el mercado mundial regido por Europa (especialmente Inglaterra y Francia) y, por tanto, en el desarrollo del capitalismo industrial. Esto reafirma la condición dependiente del capital extranjero en nuestra economía, favoreciendo a las empresas foráneas y a las oligarquías terratenientes, comerciantes y administrativas nacionales

3. Un crecimiento acelerado de las capitales urbanas en desmedro del estancamiento de las provincias y zonas rurales. 


\section{TENSION IDENT ITARIA ET N O-RACIAL}

Escuriosa, por decir lo menos, la manera en quese presentan en G abriela M istral las temáticas de esta identidad, en la que subyace la reconstitución o más bien el problema de la constitución de la misma, apreciada en su mismo origen, como escindida y violenta, con un padre conquistador y en la práctica de su descendencia, como un conformador patriarcal en ausencia, y una madre aborigen, receptáculo primario (en el sentido de "materia" o "sustancia", como lo define nuestro D iccionario de la Lengua Española), una mujer-madretierra resuelta en su apreciación del mestizaje.

La prosa mistraliana en la que se abordan temáticas referidas a los pueblos aborígenes denuestro continente coincide, en sus inicios, con la labor educativa y diplomática que M istral desarrolla en M éxico a partir de 1922. Por iniciativa del ministro de Educación pública del citado país -el filósofo y educador José Vasconcelos- es invitada a colaborar con los programas de reforma educacional - especial mente en misiones rurales e indígenas-, fomentándose así su propia motivación e interés por los temas tratados. Comienza, entonces, su producción escritural en el tema, en el marco histórico de una eclosión de movimientos indigenistas de los que forma parte importante el mismo Vasconcelos. Se estructura, entonces, una clara voluntad didáctica de apropiación modernista en esta producción de M istral, muy correspondiente al interés y proyecto intelectual fundador de estos años, mostrándose -en su caso particular- los rasgos evidentes de un proyecto misionero, educativo y evangel izador, postura con que la autora se integra explícitamente al "Arielismo" como afirmación de la latinidad frentea la expansión cultural anglosajona, adscribiéndose al planteamiento del célebre ensayo Ariel (1900) del uruguayo José Enrique Rodó4.

Lo anteriormente expuesto constituyeuna modalidad de colonidad sobre los pueblos latinoamericanos ${ }^{5}$. Sin embargo, cercana a una visión amparada en el indigenismo, propia de estos años de conformación modernista, la temática de

${ }^{4}$ A propósito del Arielismo, en una prosa titulada "H ispanoamericanismos en París: José Vasconcelos: Indología" (1927), G abriela M istral comenta sobre el momento histórico en que sepublical ndología de Vasconcelos: "C uando la pérdida de N icaragua para la raza españolalleva trazas de ser un hecho consumado. Q ueella haga lo que el 'Ariel' en hora oportunísima: deja caer su consejo de fuego: ' $O$ nos purificamos o nos perdemos: o nos juntamos codo con codo de norete a sur, o pasamos a ser la chacota del mundo llevando este rubro en la cabeza: U na raza se alquila'"' (M istral 1927: 5).

${ }^{5}$ En el ensayo Thedarker side of the renaissance: literacy, territoriality, and colonization (1995), Walter M ignolo propone tres niveles de colonización: "La colonización de lenguas", "La colonización de la memoria" y "La colonización del espacio", que se mantienen en nuestra cultura latinoamericana actual a modo de colonidad del ser. 
los textos presentes en el corpus, proviene del elemento mestizo y occidental izado que la autora representa, esto es, de una escritora chilena de las capas medias, de origen campesino; pero ya urbanizadas y en ascenso hacia una Modernidad críticamente adoptada. Así, si bien dentro de esta línea M istral rescata lo aborigen y su construcción cultural como parte importante en la conformación de los conceptos de identidades nacionales, siempre lo hace-y a pesar de sus rasgos fundacionales que parece apreciar en términos del eje mujer-madre-tierra antes señalado- dentro de los proyectos estatales que constituyen repúblicas. Esta veta de su pensamiento - la búsqueda de elementos para una concepción de una identidad republicana común a las peticiones de la M odernidad- la emparenta, salvando las ciertas, claras y consecuentes diferencias, con una generación de intelectual es que cumplieron roles importantes en el proceso de modernización desus respectivos estados como J oséV asconcelos, J osé C arlos M ariátegui, Pedro H ernández H ureña, Alfonso Reyes, etc. Reafirmo lo anterior con las palabras de la propia M istral encontradas en "El patriotismo de nuestra hora" fechado en 1919:

Chile, se ha dicho por varios hombres de estudio,...entre las naciones más importantes de América, ... es el menos democrático y el menos moderno de aquellos países. Los observadores lejanos se han engañado un poco. La herencia de Carrera, el apasionado, y la de Balmaceda, el demócrata, no se han perdido; están latentes, ... y en las nuevas leyes ambas ponen su quérotundo y febril la una, sabio y sereno la otra y de esta colaboración... nos están naciendo reformasarmónicas, hasta hace diez años, insospechadas... (M istral 1977: 159).

Así y todo, la vertiente indigenista en la obra de M istral puede reconocerse si la consideramos precisamente como una proyección de deseo, una conquista, esto es, como el ejercicio de una "voluntad" o, parafraseando a M ariátegui, "un intento de revelar el mundo indígena (que aparece fuertemente mestizado) con los atributos de otra cultura y desde una inserción social distinta: la del escritor que se sitúa en el sector más occidentalizado de la sociedad" (M ariátegui 2000: 335). Por lo anterior, agrega M ariátegui, es que la literatura indigenista "no puede darnos una versión rigurosamente verista del indio. Tiene que idealizarlo y estilizarlo....Es todavía literatura de mestizos" (M ariátegui 2000: 335). H aciendo énfasis en la última frase, diría que, entonces, es todavía una literatura que agota sus procedimientos y temas en la concordia de una visión tensional. Tal cual dice esteautor, al signar la "idealización nostál gica del pasado" (M ariátegui 2000: 335), como característica del "colonialismo", y que a mi vez interpreto como un rasgo de deslizamiento por integración: se desliza el sujeto "indio", "aborigen", hacia 
el mundo moderno, vestido, significado, como utopía ${ }^{6}$, como elemento simbólico que permite su lectura, aún más, su constitución como elemento simbólico de las modernas repúblicas, en tanto representaciones adscritas al proyecto político de la M odernidad.

Refutando lo anterior, es justamente en la prosa mistraliana donde - a pesar y acaso en razón de su tensión ginotérrea- la autora evidencia un discurso dominante, al tamente patriarcal y colonizador que conforma, como un ejesimbólico deseable y deseado, una labor evangelizadora occidental sobre los pueblos indígenas. Léanse por ejemplo los recados a fray Bartolomé de Las Casas y a Vasco de $Q$ uiroga. EI Padre de Las C asas es expuesto en el texto con la categoría de santo, incluyéndose en ella como constitución suficiente, específica, a toda la "tradición" de la conquista española: "línea de guerreros y políticos; línea de sabios y letrados; línea de santos" (M istral 1978: 171). En contraste con esta visión; pero aún más, como necesario acompañamiento, el discurso referido al indígena en estos artículos arroja una visión bastante disminuida y hasta denigrante sobre éste, con calificativos como "languidez tórrida", "nuestro fatal ismo indio", "nuestros vicios etno-raciales", "indio (pieza de difícil tratamiento)" (M istral 1978: 173). Incluso en su artículo titulado "El pueblo araucano" se refiere a ellos como "salvajes", "indiadas... enloquecidas y barbarizadas" (M istral 1994: 47). El tratamiento general que otorgan estos textos a los pueblos aborígenes es de "indios", a pesar de sacar de ellos mismos elementos (aunque en el sentido más bien de "materias") idealizados para una constitución política de la identidad. El término "indios" contiene hasta hoy una fuerte connotación negativa y denigratoria en nuestra cultura, de lo que deduzco, conforme y en relación de todo lo expuesto, que $M$ istral define lo criollo-mestizo como ideal para la identidad latinoamericana, más allá o acá del indígena. Se constituye, aś, una tensión de significación contradictoria y perturbadora en su obra, que no puede sencillamente desligarse de la tensión sexo-género ni de la tensión de lugar, es decir la utopía, como comento a propósito de las tensiones siguientes.

\footnotetext{
"Prefiero la noción de utopía como la "ontología del aún no", esto es: "Un yo que en privado y en forma consciente se representa las imágenes y circunstancias de una vida deseada, una vida que se le antoja mejor, y las proyecta hacia el futuro,... de tal suerte que en lugar de renovar la conciencia de un 'ya no', mediante la fantasía pueden ser evocadas y proyectadas en
} el mundo y la vida delas imágenes de un 'todavía no'" (Bloch 1993:5). 


\section{TEN SION IDENTIRARIA SEXO-GENERICA}

En la prosa que estudio, encuentro los elementos precisos para una develación de tensiones, que pueden leerse conforme la tesis de Sonia M ontecino, sobre el mestizaje chileno, contenida en M adresy huachos, alegorías del mestizajechileno (1991). Fundamental mente, se trata de la percepción de la imagen de la madre como presencia y la del padre como ausencia. Aunque, y conforme a las propias líneas teóricas insinuadas aquí, hablaría más bien de un eje tensional de presencia (la M adre, que sostiene el sujeto), y de un deslizamiento del Nombre del Padre, como un atributo que consigna respecto de la modalidad del $\mathrm{N}$ ombresu legitimidad.

Sostiene Sonia M ontecino que nuestro continente se caracteriza por una cultura mestiza, producto de los procesos de conquista y colonización; cultura que tendría como singularidad la fundación de un nuevo orden y de nuevos sujetos, cuyo nacimiento histórico y simbólico estuvo signado por la ilegitimidad. M ontecino plantea que esta cultura se signa por una "escena originaria", histórica unión, generalmente violenta, de la mujer india con el hombre espa ñol dentro de una relación "ilegítima" desde el punto de vista de unos y otros, trayen do como consecuencia el nacimiento de "vástagos", cuya filiación paterna era desconocida. Así los mestizos tuvieron como único referente de su origen a la madre, la cual fueen muchos casos laúnica re/productora (tanto en el sentido económico como en el social) deese mundo familiar. D esde estepunto de vista, $M$ istral representa la imagen de la mujer mestiza en "G abriela piensa en la madre ausente": "Los padres están demasiado llenos de afanes para que puedan llevarnos de la mano por un camino o subirnos a una cuesta, por eso es que somos más hijos de la madre, con la cual seguimos ceñidos..." (M istral 1992, T II: 342).

Sobre el mismo tema, es notorio en los textos que estudio un discurso de identificación de la mujer "india" con la tierra, con las lenguas aborígenes y los elementos sagrados. Lo observo precisamente en las prosas más referidas a las culturas originarias que a los colonizadores, como "A la mujer mexicana", y en los recados "Sobre M ichoacán" y "Sobre el Q uetzal cóatl", en donde diversos elementos, "materias", alimentos, artesanías, propician su identificación con lo femenino-maternal, a la vez convocando un aura de años, de misteriosa profundidad.

Esta figuración de la mujer "india" llega a convertirla en un personaje sacralizado y mitificado y es también figura que enlaza estos elementos en un proyecto presente, tal como afirma en su recado "A la mujer mexicana" G abriela M istral: 
Te han dicho que tu pureza es una virtud religiosa. También es una virtud cívica: tu vientre sustenta a la raza; muchedumbres ciudadanas nacen de tu seno calladamente con el eterno fluir de los manantiales de tu tierra... vuestra palabra no será grotesca, cobrará santidad y hará pasar por las multitudes que os oyen el calofrío de lo divino (M istral 1998: 115).

Así, la mujer, madre, educadora es portadora de una lengua primera, aborigen y, aún más, como lengua de madre, voz de la M adre, tensiona los N ombres del Padre, quedando de manifiesto, por ejemplo, en "El pueblo araucano", donde se refiere al mapudungun como "la lengua hablada por las mujeres, una lengua en gemido de tórtola sobre la extensión de los trigos, unas parrafadas de santas Antífonas sufridas" (M istral 1994: 49). Estas imágenes de la mujer (más bien imagen nuclear) son plenamente consecuentes con las exigencias del sistema sexo-género (Rubin 1986), marianista y mestizo latinoamericano, que impera en la cultura del entorno en que se inscriben los textos (entiendo la frase citada de $G$ ayle Rubin, como conjunto de prácticas, símbolos, representaciones, normas y valores sociales, que se elaboran en las sociedades a partir de la diferencia anatómica y fisiológica). Esta representación femenil ${ }^{7}$ conlleva asimismo una actitud "maternal" de servicio, amor desinteresado, entrega y sumisión, queatraviesa la obra completa de G abriela M istral. Pero es, asimismo, una representación de interior tensionado, en que se revela una forma de enfrentamiento crítico en y de la M odernidad, sobre la base de un componente genérico-sexual, ya que más allá de esos rasgos se evidencia la crítica mistraliana a la represión y subalternidad de la mujer, especialmente en los elementos de una engañosa sublimación de la maternidad ${ }^{8}$. Es, entonces, recurrente en los textos comentados la recuperación de una identidad doble, transgresora y escindida, que desliza al sujeto entre nudos de dura significación cultural. Así, la figura de la madre en las prosas seleccionadas remite a la concepción de la femineidad absorbida por la maternidad dolorosa, clásica en el marianismo cristiano, y, a la vez, a la representación de la $M$ adre-tierra, tanto en su vertiente de relación con las diosas grecolatinas, especialmente la G ea matriarcal, como con la Pachamama sagrada característica de las religiones andinas precolombinas. Confluyen tam-

${ }^{7}$ G rínor Rojo y Eliana 0 rtega usan el término femenil en sus últimos estudios, para contrastarlo con "femenino", de connotación patriarcal. También M istral suele usarlo en artículos como "La enseñanza una de las más altas poesías" (citado por 0 rtega 1990: 42).

${ }^{8} \mathrm{Algunos}$ ejemplos de esta postura se encuentran en las siguientes prosas: “Evocación de la madre", "Un na nueva organización del trabajo" , "El voto femenino", "Un viejo tema: Comentarios sobreel Informede Kinsey", "Sobre M arta Brunet", "Tiene sesenta años Selma Lagerlöff", "La instrucción dela mujer", recopilados por Pedro Pablo Z egers en La tierra tienela actitud de una mujer... (1998). 
bién las concepciones cristiana y pagana, expresando, más queuna síntesis, una permanencia de estos elementos en sus respectivos nudos de tensión: una hablante disminuida y servil ante los designios del Dios Padre, del amado y del niño (siempre masculino e identificado con el Cristo hebreo) y otra, identificada con la M adre-tierra. Esto explicaría en parte cierto "narcisismo primario", que respecto a la obra de Gabriela $M$ istral ya ha observado la crítica Eliana O rtega, entre otras; cito: "Ia presencia de un yo femenino, referido y afianzado desde la relación con la 0 tra O riginal, la madre" (0 rtega 1990: 41).

Son éstas las tensiones y deslizamientos expuestos aquí los que permiten observar que, en gran cantidad de los textos del corpus, la reconstrucción de la escena originaria de la propia unión entre el español conquistador y la madre indígena dan lugar a una simbología femenil ligada a la mujer-madre-tierra y a una simbología masculina y patriarcal, ligada al conquistador español.

Postulo, entonces, desde esta reflexión, que al gunas de las consecuencias del origen cultural latinoamericano son las figuras (en tanto imágenes, arquetipos, categorización conceptual), tensionadas y contradictorias, en el ámbito de la representación femenil, que surgen de un tipo de pensamiento propio de una cultura híbrida, amalgamada (García Canclini 1989)..

\section{TENSION IDENTITARIA UTOPICA}

Existe además, en el corpus sometido a mi estudio, otra línea de tensión permanente, que se revela especialmente en el tono nostál gico, que implica ausencia, con que se evocan los elementos naturales, en relación con el mundo rural y/o precolombino, tanto en su aspecto de soporte o pasaje como en su aspecto comunitario-social. Es notorio el tono nostálgico que implica ausencia con que se evocan los elementos naturales en paisajes referidos a M éxico, Chile y otros países latinoamericanos, lo que sitúa a la hablante en un desliz de lugar: estar y no estar, en un juego detensión por deseo y ausencia. Es decir, una hablanteque "siente" su ausencia, su otredad, en suma, su alteridad, a través de un discurso en el que se representa a la M adretierra (la naturaleza americana), como un lugar añorado, al que se quiere llegar. Un lugar que no forma parte del aquí y

${ }^{9}$ El término híbrido habla de una relación no-natural (en el sentido de cuando un hecho social puede ser asumido como natural por una sociedad) incapaz de reproducirse fuera de al gunas condiciones enteramente excepcionales para la sociedad receptora. García Canclini en su estudio Culturas híbridas. Estrategias para entrar y salir de la M odernidad (1989) intenta explicar esta hibridez como un condicionamiento triple entre los conflictos internos, dependencias exteriores y las utopías con las que estas sociedades pretenden transformar nuestras realidades. 
ahora de la hablante. Un lugar idealizado, postulado como proyecto de repre sentación social y cultural positivo, es justamente el centro de una utopía de la hablante, y que origina, entonces, que las imágenes de la $M$ adre-tierra se instalen más bien en los lugares de las otras representaciones femeniles de los mismos textos, antes de que en las figuraciones de la dicha hablante.

El hecho de que los mitos sobre la mujer-madre-tierra se representen en el plano de la alteridad, de lo otro (la mujer-madre-tierra en la prosa comentada es tercera persona, frente a la voz en primera persona que expresa una hablante sumisa, abundante en los roles femeninos simbólicos del cristianismo), y en un plano más figurado que manifiesto, revela el lugar de una función utópica refrenada en la obra de $G$ abriela $M$ istral. Este nivel de ocultamiento y figuración no sólo produce textos más retorizados en el plano metafórico, sino que revela el grado de represión de un sistema sexo-género que subalternariza y subordina a las mujeres a roles impuestos por el patriarcado. En el caso de $\mathrm{M}$ istral esto se evidencia en el mito quela crítica construyó sobre ella, como mujer sin hijos propios, al guien que sublima su maternidad frustrada con el rol dela maestra servil. Postulo que M istral tiene clara conciencia de esta discriminación, tal como lo evidencia en sus múltiples cartas y artículos, donde protesta por la situación marginal de las mujeres, especialmente, las campesinas y las escritoras.

Coincido con Beatriz Pastor Bodmer al plantear queel pensamiento utópico es, en América, el ámbito dela búsqueda y de la neutralización simbólica delos horrores de la subyugación, la opresión, la explotación y la marginalidad. Este no ha de ser confundido con la utopía hacia la que tiende, pues no es un espacio ideal, sino una dinámica de resolución de contradicciones que impul sa el pensamiento y la escritura, y a veces, sus referentes de acción, hacia la neutral ización de impasses históricos, sociales y culturales. Sería una suerte de "función utópica" (Pastor 1996), ya quela autora pone con acierto el énfasis en las figuraciones del sujeto, en su voluntad, deseo y motivaciones, y no sólo en las acciones que la llevarían al encuentro de la armonía.

Sobre la función utópica en la obra de G abriela M istral traigo a colación el juicio de Fernando Alegría, quien reconoce en la "ideología mistraliana" un elemento "americanista", expresado en la exaltación de la organización comunal indígena y la promoción de la reforma agraria (Alegría 1980). Este elemento adquiere una función utópica, por cuanto se trata más de una versión idílica, idealizada y literaria del pasado precolombino como un suerte de "edad dorada", que una versión histórica. En este sentido, el tópico de la edad dorada restituye en el plano simbólico un orden que se estima más justo, aunque nunca haya existido realmente. Dicha versión está claramente motivada por la crítica de M istral a una sociedad moderna mercantilizada, que ha hecho de la violencia y la pobreza sus mayores lacras. Por ejemplo, en "Los D erechos del $\mathrm{N}$ iño", que audazmente 
redactó en 1927 en París, reconoce el "D erecho a la tierra a todo niño que será campesino", fundamentándolo en el hecho de poseer "nuestra América, territorio generoso" y en que "nuestro latifundio corresponde a una barbarie rural" (M istral 1928: 106). Esta suerte de función utópica rural afirmada y negada, claramente se manifiesta en los recados dedicados a las culturas precolombinas; $M$ istral lo demuestra en varias prosas de las estudiadas, explicándola bien en el artículo "Algo sobre el pueblo quechua" de 1947:

La casta inca, que fue patriarcal en lo civil y matriarcal en lo religioso, tentó la utopía de abolir la miseria absoluta... C asi alcanzó al blanco imposible. No hubo ocioso en el Tihuantinsuyo (sic); cada hombre tenía cuando menos un oficio y a veces dos... Yo he recibido en mí estos rostros melancólicos que llevan en sí las marcas magulladas deuna raza que sería vencida en su alma y su cuerpo (M istral 1992, T. II: 84-5).

Este peculiar modo de pensamiento utópico le es común a M istral con una serie de escritores latinoamericanos, representativos de una tendencia artística que $\mathrm{N}$ elson 0 sorio llama "M odernismo crepuscular" (0 sorio 1996) ${ }^{10}$, situándoseen ella a las contemporáneas de $\mathrm{M}$ istral, $\mathrm{M}$ arta Brunet, Juana de I barbourou y Alfonsina Storni, guardando las diferencias de enfoque con que cada una alude a estos temas. La obra en prosa mistraliana, por la misma flexibilidad que implica el hibridismo y la situación fronteriza entrelo canónicamenteliterario y no literario, permite expresar sus posiciones críticas frente al mundo mercantilizado y cosificado, usando para ello una retórica de la figuración y del ocultamiento sobre la transgresión femenil a la maternidad. En este sentido, comparto la hipótesis de Kemy 0 yarzún respecto al problema de la identidad en los discursos literarios femeninos latinoamericanos, al afirmar que se trata de un "concepto móvil, plural, fluido y posicional; en lugar de otro-para-el-que-soy-yo, un yosotras, otras-para-las-que estamos-siendo" (0 yarzún 1993: 41). Es, entonces, en este "estar siendo" donde se fundan las identidades de esta hablante y de las representaciones femeninas en estos textos, lo que reafirma una ideología de lo femenil en tránsito.

${ }^{10} \mathrm{~N}$ elson 0 sorio se explica los discursos del M odernismo latinoamericano en las primeras décadas del siglo XX como un momento "crepuscular" en el que cabe también la obra de la $M$ istral, pues se trata de escritores que sostienen una relación problemática con los inicios de la M odernidad en América Latina, según 0 sorio: "Seforman dentro del M odernismo, imbricados en su proyecto global; pero su actividad productiva literaria se desarrolla-casi sin excepción- a partir de 1910, es decir, cuando las condiciones materiales que constituyen la base social del Modernismo entran en crisis" (0 sorio 1996: 251). 
Sobre el matiz mistraliano relativo a las oscilaciones de un sujeto en transición, Grínor Rojo lo describe muy bien en su libro Dirán que está en la gl oria... (M istral) (1997), en referencia a su pensamiento, observa "una ideología genérica en tránsito a la que es ella misma quien coloca entre los extremos de la mujer antigua y la mujer nueva" (Rojo 1997: 39). Relaciono asimismo con lo anterior, la proposición de Sigrid Weigel respecto a la mirada bizca en la literatura feme nina del siglo XX (Weigel 1986); literatura que, por una parte imponeel modelo de mujer fijado por imágenes patriarcales y, por otra, anticipa la imagen de otra mujer que en el pensamiento mistraliano se afianza más en cierto matrocentrismo simbólico, en conflicto con el modelo patriarcal.

\section{A MODO DE CONCLUSIONES}

Así, finalmente, es esta presencia de tensiones - muchas veces contradictoriasque a su vez, se resuelven en su propio interior tensionado, lo que manifiesta una característica esencial en la obra de G abriela M istral. Esta peculiar forma-pero no ajena a sus circunstancias históricas- de constitución del sujeto y de su escritura, lo reitero, es una característica fundamental, tanto en el plano de las significaciones (como he comentado) como en el plano formal, lingüístico y retórico, que procedo a reseñar brevemente.

En estos textos en prosa, e incluso en la propia poesía de $M$ istral, se manifiesta con fuerza la huella del habla típicamente rural chilena, demostrada en su preferencia por el dicho o refrán popular, el uso de hispanoamericanismos, regional ismos y coloquialismos en su discurso, la preferencia por la creación de palabras (neologismos) o el empleo corriente de otras en desuso (arcaísmos). Sólo como ejemplos, en su "Recado sobre losT lálocs" hay algunas muestras de este lenguaje: "el cultivar el maíz, el algodón y el magüey, que dan el pan de comer, el tejido arropador y la bebida de la calor..." (M istral 1992, T. II: 328) 0 expresiones como "la tierra guardada de T lálocs verdeaba siempre" (M istral 1992, T. II: 328), tienen remembranzas campesinas orales, como la atribución del artículo femenino a calor, quehaceel campesino con frecuencia. Además, el uso reiterado de la conjunción " $y$ " o el uso de diminutivos: "les echaba, a lo zumbón, una miradita verde por las ramas" (M istral 1992, T. II: 329). O tros diminutivos empleados en los recados, como padrecito, hombrecito y carnita, también remiten al habla campesina; este último tratamiento suele connotar una relación de cariño eintimidad con los personajes y cosas retratadas. N ótese que esta recurrencia no excluye el procedimiento inverso, la hipérbole, que suele dar una característica anafórica al discurso y que también evoca el habla campesina en cuanto al uso de adverbios adjetivados: "Los T lálocs eran muchos en la mucha 
tierra de M éxico" (M istral 1992, T. II: 328). Además, destaco la tendencia fre cuente al uso de pronombres clíticos redundantes, por ejemplo, en "Pequeño mapa audible de Chile": "Yo me gocéy me padecí las praderas patagónicas en el sosiego mortal de la nievey en la tragedia inútil de los vientos..." (M istral 1992, T. II: 22)

Sobre el problema de la oralidad como tensión-resistencia, lugar cultural de los pueblos autóctonos, frente a la imposición de la escritura del invasor, cabe observar que una parte significativa de lo que se llama la originalidad expresiva de G abriela M istral proviene del carácter de lenguaje hablado en su escritura, o de lo que ella defendía como la "lengua conversacional" en una conferencia titulada "Cómo escribo" (M istral 1992, T. II: 553). Es ella misma quien caracteriza sus textos titulados, significativamente, recados, "como los que llevan el tono más mío, el más frecuente, mi dejo rural con el que he vivido y con el que me voy a morir" (M istral 1938: 280).

Sostiene Carlos Pacheco que en "las comarcas orales" se dan las características siguientes: "regiones rurales aisladas", "economías agropecuarias", "culturas predominantemente orales" y "formas dialectales populares o lenguas indígenas" según la zona geográfica. Estos elementos están en permanentetensión con los "centros metropolitanos" y con sus "economías industriales" y, asimismo, con su "cultura letrada modernizada" en que dominan las normas canónicas del español o el portugués según la región. En este contexto, la presencia de las "comarcas orales" en la literatura latinoamericana aparece como una suerte de resistencia frente a la invasión de la cultura colonizadora, siendo esto característico en el "proceso histórico y cultural" Iatinoamericano del mestizaje (Pacheco 1992: 59).

Entonces, y a modo de conclusión, las tensiones constantes entre identidades relacionadas a elementos colonizadores (por ejemplo, la identificación con los conquistadores españoles en su función de "maestros") con otras más vinculadas a elementos autóctonos (por ejemplo, la identificación con las mujeres indígenas en su función de preservadoras de la cultura aborigen), revelan la conflictiva relación entre las identidades masculinas y femeninas, con la ligazón que respectivamentetienen éstas con el ámbito de lo público y de lo privado, de lo aborigen latinoamericano y lo europeo, de lo primigenio con lo moderno. Estas tensiones identitarias se vinculan finalmente con la problemática de la transculturación (Rama 1982), según la cual, "luego de la 'desculturación parcial' que se produce en el comienzo de cada oleada modernizadora y a través del ejercicio doble de la 'selectividad' y la 'invención', la amenaza aculturante cambia de signo y se transforma en motor de una 'neocultura'" (Rojo 2001: 147). Esta problemática, entonces, muestra el permanente conflicto entremodernización y autoctonismo. 


\section{BIBLIOGRAFIA}

\section{Bibliografía de la autora:}

M istral, Gabriela.

1923. "D on Vasco deQ uiroga”. El M ercurio, 23 de septiembre 1923. Santiago, Chile. P. 8.

1927. "H ispanoamericanismos en París: JoséVasconcelos: Indología". El M ercurio, 29 de mayo 1927. Santiago, Chile. P. 5.

1928. Los D erechos del Niño. Boletín de la I.M.A. O rgano de la Internacional del M agisterio Americano. T.I, N o 1: 106-107. Buenos Aires, Argentina.

1938 Tala: poemas. Buenos Aires: Sur.

1977. El patriotismo de nuestra hora. La desterrada en su patria. RoqueEsteban Scarpa. Santiago, Chile: N ascimento. Pp. 156-64.

1978. "Fray Bartolomé", en Recados para América. Textos de Gabriela M istral. Antología y presentación de M ario Céspedes. Santiago, Chile: Epesa. Pp.171-175.

1992. "Pequeño mapa audible de C hile", "Recado sobre el Q uetzalcóatl", "Recado sobre los T lálocs", "G abriela piensa en la madre ausente", "Recado sobre M ichoacán", "Algo sobre el pueblo quechua" y "Cómo escribo", en Prosa. Tomo II de Antología M ayor. Santiago, Chile: Cochrane S.A.

1994. El pueblo araucano. Gabriela M istral: Escritos políticos. Selección, prólogo y notas de Jaime Q uezada. Santiago, C hile: Tierra Firme. Pp. 45-49.

1998. A la mujer mexicana. La Tierra tienela actitud deuna mujer... Selección y prólogo de Pedro Pablo Zegers. Santiago, Chile: RIL Ediciones. Pp.115-119.

\section{Bibliografía SOBRE La aUtora:}

Alegría, Fernando. 1980. Aspectosideológi cos en losrecadosde G abriela M istral. Gabriela M istral. Introducción de M ireya Servodidio y M arcelo Coddou. Xalapa, M éxico: Universidad Veracruzana, Centro de Investigaciones Lingüístico-Literarias. Pp. 70-79.

Nómez, N aín. 1996. Antología crítica de la poesía chilena. Tomo 1: Fundación nacional, M odernismo y Crítica social. Selección, Introducción, N otas y bibliografía de N aín N ómez. Santiago, Chile: Lom, Colección entre mares.

--_-_.-. 1998. “M odernidad, racionalidad e interioridad: La poesía de mujeres a comienzos de siglo en Chile", en N omadías N 3: 10-20. Santiago, Chile: Cuarto Propio y Facultad de $\mathrm{H}$ umanidades $\mathrm{U}$. de Chile.

O rtega, Eliana. 1990. Amada amante: D iscurso femenil de Gabriela M istral. U na palabra cómplice. Encuentro con Gabriela M istral. Soledad Fariña y Raquel Olea (eds.) Ediciones de las M ujeres $N$ 02, ISIS Internacional: 41-45. Santiago, C hile.

O sorio, N elson. 1996. "Para una caracterización histórica del M odernismo crepuscuIar", en Ensayismo y M odernidad en América Latina. C arlos 0 ssandón compilador. Santiago, Chile: Libros Arcis-Lom. Pp. 243-62.

Rojo, G rínor. 1997. D irán queestá en la G loria... (M istral). Santiago, C hile: Fondo de Cultura Económica Chile. 


\section{Bibliografía teórica:}

Berman, M arshall. 1989. Brindis por la modernidad. El debate modernidad posmodernidad, $2^{2}$ edic. Buenos Aires, Argentina: N icolás C asullo compilador y editor. Pp. 67-91.

Bloch, Ernst. 1995. O ntología del aún no. Suplementos N 041 deAnthropos: 5-26. Trad. Patricia Cifre W ibrow. Barcelona, España.

García Canclini, N éstor. 1989. Culturas híbridas. Estrategias para entrar y salir de la M odernidad. Grijalbo. M éxico D.F.

Ludmer, Josefina. 1984. Tretas del débil. La sartén por el mango. Encuentro deEscritoras Latinoamericanas. G onzález, Patricia y Eliana O rtega Editoras. Puerto Rico: Ediciones H uracán. Pp. 47-54.

M ariátegui, José C arlos. 2000. "El proceso de la literatura", en Siete ensayos de interpretación dela realidad peruana. Lima, Perú: Biblioteca Amauta. Pp. 229-350.

M ignolo, Walter D . 1995. The darker side of the renaissance: literacy, territoriality, and colonization. M ichigan, USA. Ann Arbor, T he U niversity of M ichigan Press.

M ontaldo, G raciela y N elson 0 sorio. 1996. "M odernismo (H ispanoamérica)". D iccionario enciclopédico de las letras de América Latina. Vol. 2. Caracas, Venezuela: Biblioteca Ayacucho, M onte Avila Editores. Pp. 3.184 -193.

M ontecino, Sonia. 1991. M adres y huachos. Alegorías del mestizaje chileno. Santiago, Chile: Cuarto Propio/ CEDEM .

M uñoz, Luis y Dieter O elker. 1993. El M odernismo en Chile. Diccionario de movimi entos y grupos literarios chilenos. Concepción, Chile: Ediciones U niversidad de Concepción. Pp. 61-84.

O rtiz, Fernando. 1994. Contrapunteo cubano del tabaco y del azúcar. Caracas, Venezuela: Ex-Libris.

0 yarzún, Kemy. 1993. "Género y etnia: Acerca del dialogismo en América Latina". Revista Chilena de Literatura N 1:33-45. Santiago, C hile.

Pacheco, Carlos. 1992. La comarca oral. La ficcionalización dela oralidad cultural en la narrativa latinoamericana contemporánea. Caracas, Venezuela: Ediciones la C asa de Bello.

Pastor Bodmer, Beatriz. 1996. El jardín y el peregrino. Ensayos sobre el pensamiento utópico latinoamericano 1492-1965. Amsterdam, Atlanta: Editions Rodopi.

Rama, Angel. 1987. Transculturación narrativa en América Latina. M éxico: Siglo XXI.

Rojo, Grínor. 2001. Diez tesis sobre la crítica. Santiago, Chile: Lom Ediciones.

Rubin, G ayleet al. 1996. El tráfico de mujeres: N otas sobrela economía política del sexo. El género: la construcción cultural de la diferencia sexual. M éxico: U N AM . Programa Universitario de Estudios de Género: 35-95.

Subercaseaux, Bernardo. 1988. Fin de siglo: La época de Balmaceda. M odernización y cultura en Chile. Santiago, C hile: Aconcagua.

Weigel, Sigrid. 1986. La mirada bizca: Sobre la historia de la escritura de las mujeres. Estética feminista. G isela Ecker Edit. Barcelona, España: Icaria. Pp. 69-98. 